\title{
NOISE POLLUTION AND ITS CONTROL
}

\author{
Mridula Verma ${ }^{1}$, Subhashini Sharma ${ }^{2}$ \\ Associate Professor, Department of Chemistry, M.M.H College, Ghaziabad, India ${ }^{1}$ \\ Associate Professor, Department of Chemistry, M.M.H College, Ghaziabad, India²
}

\begin{abstract}
Noise pollution which is considered as the second most hazard environmental type of pollution after air pollution has been increasing day by day due to rapid urbanization and industrialization. In this noisy life situation, people try to access calm areas to take fresh breath. We need to follow the Noise Pollution (Regulation and control) Rules 2000 and subsequently amended rules on time to time for the proper management of noise pollution. The rules confirmed the need for preventing or reducing noise levels that may negatively affect human health, including annoyance and sleep disturbance. This paper provides a view of noise policies and rules in India. Noise abatement and control based on the available knowledge on noise policies and rules are also discussed in this study. The work focuses on the ambient air quality standards in respect of noise for different areas/ zones.
\end{abstract}

Keywords: Noise pollution, Noise control, Environmental pollution, Rules, Protection equipment

\section{INTRODUCTION}

Noise is derived from the Latin word nausea implying unwanted sound or sound that is loud, unpleasant or unexpected. The noise originates from human activities, especially the urbanization and the development of transport and industry. Noise pollution is one of several environmental pollutions across the world. It can be described as the propagation of noise with a harmful impact on the physiological and psychological lives of humans or animals [1]. Noise or sound pollution is usually not studied compared with other forms of pollution such as air water ,soil, light and radioactive. The reason is that the adverse effects of other forms of pollution on humans are more pronounced. According to the World Health Organization (WHO), environmental noise pollution is assessed as the second most hazard environmental type of pollution after air pollution especially in densely populated urban areas [2]. It is scientifically evidenced that exposure to high level of noise leads to many health problems and the severity of health impacts of noise and the number of people affected were presented as pyramid schematically by Babish (2002). This pyramid consists of totally six parts starting with bottom to top step as follows; feeling of discomfort (annoyance, disturbance), stress indicators (autonomous response, stress hormones), risk factors (blood pressure, cholesterol, etc.), diseases (sleep disturbance, cardiovascular) and mortality [3]. Moreover, the study focusing on the published research papers related with human reactions in changing noise conditions also stated that the annoyance is the main indicator representing the human reactions [4]. Early environmental noise control actions mostly based on the noise source emission limits and it will continue with noise control processes focusing on the noise emission limits with taking into account of public perception that is the way from noise sources to noise receivers. We need to follow the Noise Pollution ( Regulation and control) Rules 2000 and subsequently amended rules on time to time for the proper noise pollution control [5].

\section{AMBIENT AIR QUALITY STANDARDS IN RESPECT OF NOISE FOR DIFFERENT AREAS/ZONES}

(a) The ambient air quality standards in respect of noise for different areas/zones shall be such as specified in the Schedule annexed to Noise Pollution ( Regulation and control) Rules 2000 [5].

(b) The State Government (shall categorize) ${ }^{\mathrm{s}}$ the areas into industrial, commercial, residential or silence areas/zones for the purpose of implementation of noise standards for different areas [6].

(c) The State Government shall take measures for abatement of noise including noise emanating from vehicular movements, (blowing of horns, bursting of sound emitting fire crackers, use of loud speakers or public address system and sound producing instruments) and ensure that the existing noise levels do not exceed the ambient air quality standards specified under these rules [7].

(d) All development authorities, local bodies and other concerned authorities while planning developmental activity or carrying out functions relating to town and country planning shall take into consideration all aspects of noise pollution 


\section{International Advanced Research Journal in Science, Engineering and Technology \\ Impact Factor 7.105 ㄷ Vol. 9, Issue 1, January 2022 \\ DOI: 10.17148/IARJSET.2022.9108}

as a parameter of quality of life to avoid noise menace and to achieve the objective of maintaining the ambient air quality standards in respect of noise.

\section{RESPONSIBILITY AS TO ENFORCEMENT OF NOISE POLLUTION CONTROL MEASURES}

(a) The noise levels in any area/zone shall not exceed the ambient air quality standards in respect of noise as specified in the Schedule [5].

(b) The authority shall be responsible for the enforcement of noise pollution control measures and the due compliance of the ambient air quality standards in respect of noise.

(c) The respective State Pollution Control Boards or Pollution Control Committees in consultation with the Central Pollution Control Board shall collect, compile and publish technical and statistical data relating to noise pollution and measures devised for its effective prevention, control and abatement[8].

\section{RESTRICTIONS ON THE USE OF LOUD SPEAKERS /PUBLIC ADDRESS SYSTEM (AND SOUND PRODUCING INSTRUMENTS)}

(a) A loud speaker or a public address system shall not be used except after obtaining written permission from the authority.

(b) A loud speaker or a public address system or any sound producing instrument or a musical instrument or a sound amplifier shall not be used at night time except in closed premises for communication within, like auditoria, conference rooms, community halls or during a public emergency [7].

(c) Notwithstanding anything contained in sub-rule (2), the State Government may subject to such terms and conditions as are necessary to reduce noise pollution, permit use of loud speakers or public address systems and the like during night hours (between 10.00 p.m. to 12.00 midnight) on or during any cultural, religious or festive occasion of a limited duration not exceeding fifteen days in all during a calendar year and the concerned State Government or District Authority in respect of its jurisdiction as authorized by the concerned State Government shall generally specify in advance, the number and particulars of the days on which such exemption should be operative. Explanation.- For the purposes of this sub-rule, the expressions-

(i) Festive occasion shall include any National function or State function as notified by the Central Government or State Government.

(ii) National function or State function shall include - (A) Republic Day; (B) Independence Day; (C) State Day; or (D) such other day as notified by the Central Government or the State Government [9].

(d) The noise level at the boundary of the public place, where loudspeaker or public address system or any other noise source is being used shall not exceed $10 \mathrm{~dB}(\mathrm{~A})$ above the ambient noise standards for the area or $75 \mathrm{~dB}(\mathrm{~A})$ whichever is lower;

(e) The peripheral noise level of a privately owned sound system or a sound producing instrument shall not, at the boundary of the private place, exceed by more than $5 \mathrm{~dB}(\mathrm{~A})$ the ambient noise standards specified for the area on which it is used [7].

\section{RESTRICTIONS ON THE USE OF HORNS, SOUND EMITTING CONSTRUCYION EQUIPMENTS AND BURSTING OF FIRE CRACKERS}

(a) No horn shall be used in silence zones or during night time in residential areas except during a public emergency.

(b) Sound emitting fire crackers shall not be burst in silence zone or during night time.

(c) Sound emitting construction equipments shall not be used or operated during night time in residential areas and silence zones[7]. 


\section{International Advanced Research Journal in Science, Engineering and Technology \\ Impact Factor $7.105 \div$ Vol. 9, Issue 1, January 2022 \\ DOI: $10.17148 /$ IARJSET.2022.9108}

\section{CONSEQUENCES OF ANY VIOLATION IN SILENCE ZONE/AREA}

Whoever, in any place covered under the silence zone/area commits any of the following offence, he shall be liable for penalty under the provisions of the Act:

(a) whoever, plays any music or uses any sound amplifiers,

(b) whoever, beats a drum or tom-tom or blows a horn either musical or pressure, or trumpet or beats or sounds any instrument, or

(c) whoever, exhibits any mimetic, musical or other performances of a nature to attract crowds.

(d) whoever, bursts sound emitting fire crackers; or

(e) whoever, uses a loud speaker or a public address system [7].

\section{COMPLAINTS TO BE MADE TO THE AUTHORITY}

(a) A person may, if the noise level exceeds the ambient noise standards by $10 \mathrm{~dB}(\mathrm{~A})$ or more given in the corresponding columns against any area/zone or, if there is a violation of any provision of these rules regarding restrictions imposed during night time, make a complaint to the authority [7].

(b) The authority shall act on the complaint and take action against the violator in accordance with the provisions of these rules and any other law in force.

\section{POWER TO PROHIBIT ETC. CONTINUANCE OF MUSIC SOUND OR NOISE}

(a) If the authority is satisfied from the report of an officer in-charge of a police station or other information received by him including from the complainant that it is necessary to do so in order to prevent annoyance, disturbance, discomfort or injury or risk of annoyance, disturbance, discomfort or injury to the public or to any person who dwell or occupy property on the vicinity, he may, by a written order issue such directions as he may consider necessary to any person for preventing, prohibiting, controlling or regulating [8].

(1) The incidence or continuance in or upon any premises of -

(i) Any vocal or instrumental music,

(ii) Sounds caused by playing, beating, clashing, blowing or use in any manner whatsoever of any instrument including loudspeakers, public address systems, horn, construction equipment, appliance or apparatus or contrivance which is capable of producing or re-producing sound [7].

(iii) sound caused by bursting of sound emitting fire crackers[7].

(2) the carrying on in or upon, any premises of any trade, avocation or operation or process resulting in or attended with noise.

(b) The authority empowered under sub-rule (1) may, either on its own motion, or on the application of any person aggrieved by an order made under sub-rule (1), either rescind, modify or alter any such order: Provided that before any such application is disposed of, the said authority shall afford to the applicant and to the original complainant, as the case may be an opportunity of appearing before it either in person or by a person representing him and showing cause against the order and shall, if it rejects any such application either wholly or in part, record its reasons for such rejection [8].

\section{IX . CONTROL OF NOISE POLLUTION}

Noise generation is associated with most of our daily activities. A healthy human ear responds to a very wide range of Sound Pressure Level (SPL) from the threshold of hearing at zero dB, uncomfortable at 100-120 dB and painful at 130-140 dB [10]. Due to the various adverse impacts of noise on humans and environment noise should be controlled. 


\section{International Advanced Research Journal in Science, Engineering and Technology \\ Impact Factor 7.105 ㄷ Vol. 9, Issue 1, January 2022 \\ DOI: 10.17148/IARJSET.2022.9108}

The technique or the combination of techniques to be employed for noise control depend upon the extent of the noise reduction required, nature of the equipment used and the economy aspects of the available techniques. The various steps involved in the noise management strategy are as follows. Reduction in the noise exposure time or isolation of species from the sources form part of the noise control techniques besides providing personal ear protection, engineered control for noise reduction at source and/or diversion in the trajectory of sound waves. The techniques employed for noise control can be broadly classified as follows $[11,12,13]$.

\section{A. NOISE CONTROL at SOURCE}

The noise pollution can be controlled at the source of generation itself by employing techniques like-

\section{(1). REDUCING the NOISE LEVELS FROM DOMESTIC SECTORS:}

The domestic noise coming from radio, tape recorders, television sets, mixers, washing machines, cooking operations can be minimised by their selective and judicious operation. By usage of carpets or any absorbing material, the noise generated from felling of items in house can be minimised.

\section{(2). MAINTENANCE of AUTOMOBILES:}

Regular servicing and tuning of vehicles will reduce the noise levels. Fixing of silencers to automobiles, two wheelers etc., will reduce the noise levels.

\section{(3). CONTROL OVER VIBRATIONS :}

The vibrations of materials may be controlled using proper foundations, rubber padding etc. to reduce the noise levels caused by vibrations.

\section{(4). LOW VOICE SPEAKING :}

Speaking at low voices enough for communication reduces the excess noise levels.

\section{(5). PROHIBITION on USAGE of LOUD SPEAKERS:}

By not permitting the usage of loudspeakers in the habitant zones except for important meetings / functions.

\section{(6). SELECTION of MACHINERY :}

Optimum selection of machinery tools or equipment reduces excess noise levels. For example selection of chairs, or selection of certain machinery/equipment which generate less noise (Sound) due to its superior technology etc. is also an important factor in noise minimisation strategy.

\section{(7). MAINTENANCE of MACHINES:}

Proper lubrication and maintenance of machines, vehicles etc. will reduce noise levels.

For example, it is a common experience that, many parts of a vehicle will become loose while on a rugged path of journey. If these loose parts are not properly fitted, they will generate noise and cause annoyance to the driver/passenger. Similarly is the case of machines. Proper handling and regular maintenance is essential not only for noise control but also to improve the life of machine.

\section{B. CONTROL in the TRANSMISSION PATH}

The change in the transmission path will increase the length of travel for the wave and get absorbed /refracted / radiated in the surrounding environment. The available techniques are briefly discussed below.

\section{INSTALLATION of BARRIERS :}

Installation of barriers between noise source and receiver can attenuate the noise levels. For a barrier to be effective, its lateral width should extend beyond the line-of-sight at least as much as the height. The barrier may be either close to the source or receiver, to increase the traverse length for the sound wave. It should also be noted that the presence of the barrier itself can reflect sound back towards the source. At very large distances, the barrier becomes less effective because of the possibility of refractive atmospheric effects.

\section{DESIGN of BUILDING:}

The design of the building incorporating the use of suitable noise absorbing material for wall/door/window/ceiling will reduce the noise levels.

(a). Installation of panels or enclosures: A sound source may be enclosed within a paneled structure such as room as a means of reducing the noise levels at the receiver. The actual difference between the sound pressure levels inside and 


\section{International Advanced Research Journal in Science, Engineering and Technology \\ Impact Factor 7.105 다. 9, Issue 1, January 2022 \\ DOI: 10.17148/IARJSET.2022.9108}

outside an enclosure depends not only on the transmission loss of the enclosure panels but also on the acoustic absorption within the enclosure and the details of the panel penetrations which may include windows or doors. The product of frequency of interest and surface weight of the absorbing material is the key parameter in noise reduction through transmission loss. With conventional construction practices, the high-frequency transmission loss of a panel becomes limited to around $40 \mathrm{~dB}$, owing to the transmission of sound through flanking paths other than the panel itself. Examples of such flanking are structural connections or ducts joining the two spaces on either side of the panel of interest [13].

(b). Green belt development: Green belt development can attenuate the sound levels. The degree of attenuation varies with species of greenbelt (shrubs and trees). The statutory regulations direct the industry to develop greenbelt four times the built-up area for attenuation of various atmospheric pollutants, including noise.

\section{USING PROTECTION EQUIPMENT:}

Protective equipment usage is the ultimate step in noise control technology, i.e. after noise reduction at source and/or after the diversion or engineered control of transmission path of noise. The first step in the technique of using protective equipment is to gauge the intensity of the problem, identification of the sufferer and his exposure to the noise levels. The usage of protective equipment and the worker's exposure to the high noise levels can be minimised by following methods.

(a). Job rotation: By rotating the job between the workers working at a particular noise source or isolating a person, the adverse impacts can be reduced.

(b). Exposure reduction: Regulations prescribe that, noise level of $90 \mathrm{~dB}$ (A) for more than 8 hr continuous exposure is prohibited. Persons who are working under such conditions will be exposed to occupational health hazards. The schedule of the workers should be planned in such a way that, they should not be over exposed to the high noise levels.

(c). Hearing protection: Equipment like earmuffs, ear plugs etc. are the commonly used devices for hearing protection. Attenuation provided by ear-muffs vary widely in respect to their size, shape, seal material etc. Literature survey shows that, an average noise attenuation up to $32 \mathrm{~dB}$ can be achieved using earmuffs [14] .

\section{CONCLUSION}

Noise pollution adversely affects the human being leading to irritation, loss of concentration, loss of hearing. In this study, the focus was on the Noise Pollution and its control. We have discussed the functional elements involved in Noise Pollution and its control (i.e. Ambient air quality standards in respect of noise for different areas/zones, Responsibility as to enforcement of noise pollution control measures, Restrictions on the use of loud speakers/public address system and sound producing instruments, Restrictions on the use of horns, sound emitting construction equipments and bursting of fire crackers, Consequences of any violation in silence zone/area, Complaints to be made to the authority, Power to prohibit etc. continuance of music sound or noise, Control of Noise Pollution) to reduce the impact of noise pollution on public health and the environment. Identify the sources of noise pollution. Once identified, the reasons for increased noise levels to be assessed. Now, efforts shall be made to reduce the undesired noise levels from (unwanted) noise generating sources. The result of the study demonstrate the need for strict enforcement of legal provisions and a better environment system for the control of Noise Pollution. Provision of a Noise pollution control planning and monitoring system is a prerequisite issue for effective reduction of noise pollution associated risks.

\section{REFERENCES}

[1]. Oloruntoba EO, Ademola RA, Sridhar MKC, Agbola SA, Omokhodion FO, Ana GREE, Alabi RT. Urban environmental noise pollution and perceived health effects in Ibadan, Nigeria. Afr J Biomed Res. 2012; 15(2):77-84.

[2]. World Health Organization (WHO), 2011. Burden Of Disease From Environmental Noise. Quantification Of Health Life Years Lost İn Europe, WHO, Joint Research Center, Denmark.

[3]. W. Babisch, 2002. The noise/stress concept, risk assessment and research needs. Noise \& Health 4(16), 1-11.

[4]. H. E. Laszlo, E. S. McRoble, S. A. Stansfeld, A. L. Hansell, 2012. Annoyance and other

reaction measures to changes in noise exposures - A Review. Science Of The Total Environment 435-436, 551-562.

[5]. Gazette of India. S.O. 123(E) dated 14 February 2000, The Noise Pollution (Regulation and Control) Rules, 2000, Ministry of Environment and Forests, Government of India, New Delhi, India. 2000 


\section{International Advanced Research Journal in Science, Engineering and Technology \\ Impact Factor $7.105 \div$ Vol. 9, Issue 1, January 2022 \\ DOI: 10.17148/IARJSET.2022.9108}

[6]. Gazette of India. S.O. 1046 (E) dated 22 November 2000, The Noise Pollution (Regulation and Control) Amendment Rules, 2000, Ministry of Environment and Forests, Government of India, New Delhi, India. 2000 [7]. Gazette of India. S.O. 50 (E) dated 11 January 2010, The Noise Pollution (Regulation and Control) (Amendment) Rules, 2010, Ministry of Environment and Forests , Government of India, New Delhi, India. 2010 [8]. Gazette of India. S.O. 1569 (E) dated 19 September 2006, The Noise Pollution (Regulation and Control) Amendment Rules, 2006, Ministry of Environment and Forests, Government of India, New Delhi, India. 2006 [9]. Gazette of India. S.O. 2555 (E) dated 10 August 2017, The Noise Pollution (Regulation and Control) Amendment Rules, 2017, Ministry of Environment ,Forests and Climate change , Government of India, New Delhi, India. 2017

[10]. Industrial Safety and Pollution Control Handbook, Associate (Data) Publishers Pvt., Secunderabad, 1991 ed.

[11]. Muralikrishna, K V S G, Air Pollution and Control, Kaushal \& Co., Kakinada, AP, 1995 ed.

[12]. Rao, P.R., Noise Pollution and Control, Encyclopedia of Environmental Pollution and Control, Vol.-2, Environ media Publications, India, 1995 ed.

[13]. Franken A. Peter, Community Noise Pollution, Industrial Pollution, Van Noistrand Reinhold Company, New York, 1974 ed.

[14]. Mathur, J.S.B., Noise Control : Legislation, Planning and Design, Industrial Effluent Treatment, Vol.:2, Applied Science Publishers Ltd., London, 1981 ed. 